\title{
Congenital myasthenic syndromes and myasthenia gravis are challenging diagnoses in neurological practice
}

\author{
Síndromes miastênicas congênitas e miastenia Grave são diagnósticos desafiadores na \\ prática neurológica
}

Anamarli Nucci

\author{
Universidade Estadual de \\ Campinas, Departamento de \\ Neurologia, Campinas SP, Brasil. \\ Correspondence: \\ Anamarli Nucci; Departamento de \\ Neurologia, Universidade Estadual \\ de Campinas; R. Tessália Vieira \\ de Camargo, 126;13083-887 \\ Campinas SP, Brasil; \\ E-mail:anucci@hc.unicamp.br \\ Conflict of interest: \\ There is no conflict of interest to \\ declare. \\ Received 22 August 2016 \\ Accepted 29 August 2016
}

(cc) BY

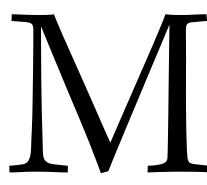

yasthenia is abnormal fatigability on exertion that is present in a variety of syndromes and diseases with different pathogenesis due to autoantibodies, toxins, drugs and genetic defects. They all have in common a deficient coupling of excitation-contraction in the neuromuscular junction (NMJ), either in its presynaptic, synaptic or postsynaptic regions ${ }^{1}$.

Acquired autoimmune myasthenia gravis $(\mathrm{MG})$ is the most prevalent myasthenia type, and is a postsynaptic NMJ's disorder, with heterogeneous clinical and antibodies presentation ${ }^{2}$. Antibody against the nicotinic acetylcholine receptor (AChR) was the first discovered and it is present in about $85 \%$ of generalized MG or in $50 \%$ in ocular MG, which is AChR-MG ${ }^{2}$. AChR-MG shows decremental compound muscle action potential (CMAP) on repetitive nerve stimulation at $2-3 \mathrm{~Hz}$ and when this exam is negative, the single-fiber electromyography increases the chances of diagnose ${ }^{1}$. Distinction between thymomatous- and nonthymomatous-MG, especially in the elderly with late onset MG, is absolutely necessary, since the first one is managed with oncologic therapy as well. Nonthymomatous-MG can be treated with acetylcholinesterase inhibitors, immunosuppressive drugs ${ }^{2}$ and thymectomy ${ }^{3}$.

In $40 \%$ of seronegative-AChR-MG (SNMG), using standard radioimmunoassay, the serum antibody directed to the muscle-specific tyrosine kinase (MuSK) is positive, characterizing the subgroup of MuSK-MG ${ }^{2}$. The clinical characteristics of MuSK-MG are facial, bulbar and neck fatigable weakness, partial response to acetylcholinesterase inhibitors, response to rituximab in some patients and, no abnormalities in thymus ${ }^{2}$.

Recently, a third autoantibody was found in 4 to $45 \%$ of double-SNMG cases, this large range of variation is due to the methods employed ${ }^{2,4}$. The low-density lipoprotein receptor-related protein 4 (Lrp4), a receptor for agrin, is the target of this antibody. Authors ${ }^{4}$ found $14.3 \%$ of positive Lrp4 antibody in an Italian series of 55 double-SNMG patients and clinical correlation for Lrp4-MG is thus emerging: female patients with mild or moderate myasthenia, according to Myasthenia Gravis Foundation of America scores, and without specific thymus abnormalities $^{4}$. However, to draw more definitive conclusions, further efforts are needed in collecting more data through larger series.

Lambert-Eaton myasthenic syndrome (LEMS) and botulism are presynaptic NMJ's dysfunction with autoimmune and toxic pathogenesis, respectively ${ }^{1}$. In LEMS an antibody against $\mathrm{P} / \mathrm{Q}$ type voltage-gated calcium channel is positive in patients with small-cell lung cancer and other tumors or in patient without any neoplasia (even after a long lasting follow-up). Fatigability is predominant in limb girdle, frequently associated with hyporreflexia and autonomic dysfunctions ${ }^{2}$. Repetitive nerve stimulation is characteristic ${ }^{1}$.

Congenital myasthenic syndromes (CMS) are rarer than MG and their onset occurs at birth, shortly after it or in early childhood. Their pathogenesis is related to genetic defects affecting structural and functional NMJ's proteins, inherited more frequently as autosomal recessive trace ${ }^{5}$. CMS diagnosis is based on detailed clinical findings and confirmed upon detection of the CMAP decrement on $2-3 \mathrm{~Hz}$ nerve stimulation ${ }^{1}$ (eventually double CMAP in single stimulus, disappearing after brief voluntary contraction ${ }^{6}$ ) or increased/blocking jitter 
on single-fiber electromyography ${ }^{1}$. Other two criteria must be considered, absence of serum antibodies and no improvement with immunosuppressive therapy ${ }^{1}$. Thus, detailed clinical and neurophysiological exams raise the hypothesis of CMS. Next generation sequencing of genes may confirm the already known CMS subtypes or whole-exome sequencing may suspect a new causative gene ${ }^{7}$.

In 2009 a Brazilian case-report of end-plate acetylcholinesterase deficiency with proven genetic mutation was published ${ }^{6}$, and a year later, a CMS series of cases came from the Southern region ${ }^{8}$. The authors estimated a minimum prevalence of 0.18 cases per 100.000 in the State of Parana and the most frequent mutation was in CHRNE gene, which is responsible for coding the $\varepsilon A C h R$ subunit. The second mutation in frequency was documented in $D O K 7$ gene $^{8}$. Interestingly, the same mutation was observed in Spain and Portugal, nations with significant role in the immigration process of the mentioned area. Since our large country has regions of different ethnic background, it will be of practical importance to uncover the genetic epidemiology of CMS in other regions of Brazil.

In this issue of Arquivos de Neuropsiquiatria, Souza et al. ${ }^{9}$ present a comprehensive review on CMS that will be of great interest to the readers, as they included clinic, genetic and therapeutic particularities according to CMS subtypes.

CMS mostly manifest in the first two years of life, leading to difficulties in the differential diagnose with congenital myopathies. Not to mention that same congenital myopathies may still be associated with myasthenic symptoms ${ }^{10}$. Another great challenge is differentiate between CMS and early onset AChR-MG or with MusK-MG, when they are seronegative.

Considering the importance of genetic testing in the final diagnose of $\mathrm{CMS}^{8,9}$ and that it is costly and only available in few centers of Brazil, it seems to be of a high demand to reverse this situation. Early and definite diagnoses in CMS lead to a better rational therapeutic choice in benefit to patients.

\section{References}

1. Amato AA, Dumitru D. Neuromuscular junction disorders. In: Dumitru D, Amato AA, Zwarts MJ (eds). Electrodiagnostic medicine. 2nd ed. Philadelphia: Hanley \& Belfus; 2002. p. 1127-212.

2. Binks S, Vincent A, Palace J. Myasthenia gravis: a clinical-immunological update. J Neurol. 2016;263(4):826-34. doi:10.1007/s00415-015-7963-5

3. Wolfe Gl, Kaminski HJ, Aban IB, Minisman G, Kuo HC, Marx A et al. Randomized trial of thymectomy in myasthenia gravis. N Engl J Med. 2016;375(6):511-22. doi:10.1056/NEJMoa1602489

4. Marino M, Scuderi F, Samengo D, Saltelli G, Maiuri MT, Shen C et al. Flow cytofluorimetric analysis of anti-LRP4 (LDL Receptor-Related Protein 4) autoantibodies in Italian patients with myasthenia gravis. PLoS One. 2015;10(8):e0135378. doi:10.1371/journal.pone.0135378

5. Engel AG, Shen XM, Selcen D, Sine SM. Congenital myasthenic syndromes: pathogenesis, diagnosis, and treatment. Lancet Neurol. 2015;14(4):420-34. doi:10.1016/S1474-4422(14)70201-7

6. Lorenzoni PJ, Scola RH, Gervini BL, Kay CSK, Werneck LC. Electrophysiological study in synaptic congenital myasthenic syndrome: end-plate acetylcholinesterase deficiency. Arq Neuropsiquiatr 2009;67(2b):502-4. doi:10.1590/S0004-282X2009000300024

7. O'Connor E, Töpf A, Müller JS, Cox D, Evangelista T, Colomer J et al. Identification of mutations in the MYO9A gene in patients with congenital myasthenic syndrome. Brain. 2016;139(8):2143-53. doi:10.1093/brain/aww130

8. Mihaylova V, Scola RH, Gervini B, Lorenzoni PJ, Kay CK, Werneck LC et al. Molecular characterisation of congenital myasthenic syndromes in Southern Brazil. J Neurol Neurosurg Psychiatry. 2010;81(9):973-7. doi:10.1136/jnnp.2009.177816

9. Souza PVS, Batistella GNR, Lino VC, Pinto WBVR, Annes M, Oliveira ASB Clinical and genetic basis of congenital myasthenic syndromes. Arq Neuropsiquiatr. 2016;74(9):750-60. doi:10.1590/0004-282X20160106

10. Rodriguez Cruz PM, Sewry C, Beeson D, Jayawant S, Squier W, McWilliam R et al. Congenital myopathies with secondary neuromuscular transmission defects: a case report and review of the literature. Neuromuscul Disord. 2014;24(12):1103-10. doi:10.1016/j.nmd.2014.07.005 